\title{
WeCare Project: Development of Web-based Platform for Online Psychological Consultation using Scrum Framework
}

Frisca Febriyani Kurniawan ${ }^{1}$, Fauzan Radifan Shidiq ${ }^{2}$, Edi Sutoyo ${ }^{3}$

1,2,3 Department of Information Systems, Telkom University, Indonesia

\begin{tabular}{l} 
Article Info \\
\hline Article history: \\
Received Apr 29, 2020 \\
Revised May 16, 2020 \\
Accepted Jun 11, 2020 \\
\hline
\end{tabular}

\section{Keywords:}

Information Systems

Web Application

Agile Methodology

Scrum

\begin{abstract}
Symptoms and signs of mental disorders depend on the type of disorder experienced. Patients can experience interference with emotions, thought patterns, and behavior. Ways to determine the diagnosis and check whether you have a mental illness, there are several ways in the form of physical examination through a doctor, laboratory tests, psychological evaluation. There is also therapy as a healing process and recovery of the soul that is healthy. In Indonesia, many people experience mental health problems, but most are not aware of and care about these problems. Even in the worst cases, many cases lead to suicide. One factor that triggers suicide is, people who experience mental health problems do not have a place to talk about the problems they are facing, because in each city itself not all the availability of psychologist services that can help sufferers of mental health problems, let alone remember the price of psychologist services offered is quite expensive. Therefore, by taking into account these considerations, the WeCare project proposes developing a web-based platform for online psychologist consultation. In general, this platform has three main actors namely, admin, user, and psychologist. This platform is expected to be a media liaison between users (patients) with psychologists in conducting consultations.
\end{abstract}

This is an open access article under the CC BY-SA license.

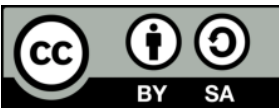

\section{Corresponding Author:}

Frisca Febriyani Kurniawan,

Department of Information Systems, Telkom University,

Jl. Telekomunikasi, Sukapura, Kec. Dayeuhkolot, Bandung, Indonesia

Email: friscafk@student.telkomuniversity.ac.id

\section{INTRODUCTION}

The term mental health is taken from the concept of mental hygiene, while the word mental is taken from Greek, the meaning is the same as psyche in Latin, which means psychological, mental, or psychological [1]. Mental hygiene refers to the ability of individuals to adapt themselves, with others, society, and the environment. So that harmony can be realized, and able to deal with problems that can occur, and finally individuals feel satisfied and able (maladjustment). So, mental health is the most important aspect of one's life [2]. A person's mental health is influenced by two factors, namely internal factors, and external factors. Internal factors include personality, physical condition, psychological maturity, attitude to face life problems. As for external factors including economic conditions, culture, family environment conditions, community environmental conditions, educational environment. Several psychological aspects also influence mental health are as follows [3]:

- Individual Initial Experience

Initial experience is the experiences that occur in someone, especially those that occurred in his past. This initial experience is an important and even crucial part for an individual's mental state 
in the future. Various studies have found that people who experience mental disorders, caused by the inability of a person to meet their needs.

- Mental Disorders and Diseases

Mental health disorders according to psychology, usually associated with mental disorders or stress. This condition is considered abnormal in human development

Mental health problems or mental illness can cause various emotional symptoms, weight loss, malnutrition, electrolyte imbalance caused by vomiting by yourself. Ways to determine the diagnosis and check whether you have a mental illness, there are several ways in the form of physical examination through a doctor, laboratory tests, psychological evaluation. There is also therapy as a healing process and recovery of the soul that is healthy. Examples of holistic therapy are therapies that do not only use drugs and are aimed at mental disorders, religious psychotherapy in the form of therapy given by re-studying and practicing religious teachings, pharmacotherapy using drugs by prescription doctors, behavioral therapy so that patients change both attitudes and behavior towards scary object or situation [4].

In Indonesia, many people experience mental health problems, but most are not aware of and care about these problems. Even in the worst cases, many cases lead to suicide. Deaths from suicide in Indonesia are predicted to be the highest in Southeast Asia. One of the factors triggering suicide is people who experience mental health problems do not have a place to talk about the problems they are facing, because in every city itself not all the availability of psychologist services that can help sufferers of mental health problems, especially considering the price psychologist services offered are quite expensive [5], [6].

The development of information technology at this time has been developing very rapidly in a society wherein the development of information technology has become a part of people's lives today. The development of information technology has penetrated various institutions both government, education, banking, or private, and one of them in the field of services, including consulting services [7]-[10]. Therefore, by taking into account these considerations, the WeCare project proposes developing a web-based platform for online psychologist consultation. In general, this platform has three main actors namely, admin, user, and psychologist. This platform is expected to be a media liaison between users (patients) with psychologists in conducting consultations.

\section{RESEARCH METHOD}

\subsection{Information Systems}

According to McLeod [11], a system is a group of elements that are integrated with the same goal to achieve goals. The information is data that is processed into a form more useful and more meaningful for those who receive it. Information is also called data that is processed or data that has meaning. Information is data that has been processed in such a way as to increase the knowledge of someone who uses it. Decision-makers understand that information is a critical factor in determining success or failure in a line of business. Any system without information will not be useful, because the system will experience traffic jams and eventually stop. Information can be raw data, structured data, the capacity of an information channel, and so on.

Information systems are a regular combination of people, hardware, software, communication networks, and data resources that collect, change, and disseminate information in an organization. Another understanding of an information system is a system within an organization that meets the needs of daily transaction data processing, supporting operations, managerial and strategic activities of an organization, and providing certain external parties with the reports required.

Information systems can also be defined as a system made by humans that consists of components in the organization to present information. The information system is an information generating system, then with integration between sub-systems, the information system will be able to provide quality, precise, fast, and accurate information in accordance with the management that needs it. In a computer-based environment, information systems use computer hardware and software, telecommunications networks, database management, and various other forms of information technology intending to convert data sources into various kinds of information needed 
by users. Simply stated, the data is processed into information. And in the next stage, an information will become data for the creation of other information.

\subsection{Unified Modeling Language (UML)}

According to Kruchten [12], UML is a graphic language for visualizing, specifying, constructing, and documenting every artifact of a software system. Cockburn [13] explained that Usecase is a contract for behavior. The contract defines how an actor uses a computer-based system to solve the problems he faces.

Activity Diagrams model business process workflows and sequences of activities in a process. This diagram is very similar to a flowchart because it models workflows from one activity to another or from activity to status. It is advantageous to make an Activity Diagram early in the modeling process to help understand the whole process. Activity diagrams are also useful for describing parallel behavior or describing interactions between several use cases. Sequence diagrams depict interactions between objects in and around the system (including users, displays, etc.) in the form of messages that are represented against time [14].

Sequence diagrams consist of vertical dimensions (time) and horizontal dimensions (objects related to each other). Sequence diagrams are used to illustrate a scenario or series of steps performed in response to an event to produce a certain output. Starting from what triggers these activities, what processes and changes occur internally, and what outputs are produced. Each object, including the actor, has a vertical lifeline. The message is described as an arrow line from one object to another. In the next design phase, the message will be mapped to the operations/methods of the class. Activation bar shows the length of time a process is executed, usually starting with the receipt of a message [15], [16].

\subsection{Agile Methodology}

An agile methodology is a group of methods in software development that is based on the same principles or short-term system development that requires rapid adaptation from the developer to changes that occur in any form [17]. In 2001, 17 pioneers of the agile methodology met at the Snowbird Ski Resort, Utah, and compiled a joint manifesto on this methodology [18]. This manifesto then became the basic principle of agile, with an emphasis on communication and collaboration, software functions, and flexibility to adapt to emerging business realities. But from the manifesto, it was not stated about the concrete process, how when the development team had to meet with some problems that would arise, namely: deadlines, stakeholders, and pressure in the development process.

\subsection{Scrum}

Scrum is a framework for developing a complex product, where the vision of Scrum is to make highvalue products in terms of creativity and productivity. Scrum is based on an empirical control theory called empiricism, which emphasizes that knowledge is gained from experience so decision making should be based on that knowledge. Scrum uses an iterative and incremental approach to anticipate uncertainty in projects and risk control [19].

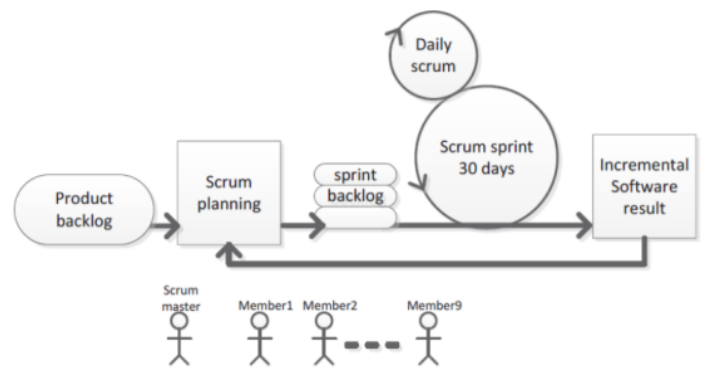

Figure 1: Scrum Model

Figure 1 illustrates the stages of Scrum, the details are as follows:

1. Product backlog

Product Backlog is an ordered list of all things that have been known to date in the product. Product Backlog is the only source of the need for all changes that need to be applied to the product. The product owner is responsible for the product backlog, including its contents, availability, and order.

2. Sprint

Sprint is a time limit of one month or less in duration, where there is a "complete" Increment making process, can be used, and has the potential to be released. Sprint has a consistent duration throughout the product development life cycle. The new sprint starts immediately after the previous sprint is finished. The results of sprint planning are the sprint backlog and the sprint goal [20]. 
a. Sprint Backlog

The Sprint Backlog is a list of product backlog items selected for the sprint plus plans to deliver increments and achieve sprint goals. The sprint backlog is a forecast from the development team regarding the functionality that will go into the next increment and the work that needs to be done to deliver the functionality to a "finished" increment.

b. Sprint Goal

Sprint Goal is an objective for sprints that can be achieved through implementing a product backlog. Sprint Goal is a guide for development teams to answer the question of why they develop increments.

3. Daily Scrum

Daily Scrum is a 15-minute meeting per day to evaluate what is done, the obstacles that exist, and the target of completion for the next meeting material.

4. Sprint Review

Sprint Review is the delivery of software increments to the customer, which is demonstrated and evaluated by the customer. The increment is a manifestation of a product backlog item that is completed in a sprint and the total business value of the increment of all past sprints. At the end of the sprint, the new increment must be "finished", which means the increment must be in a usable condition and in accordance with the Scrum Team's definition of "finish".

\section{RESEARCH METHOD}

\subsection{Research Framework}

In this research framework, several stages will be explained to achieve the objectives, as illustrated in Figure 2.

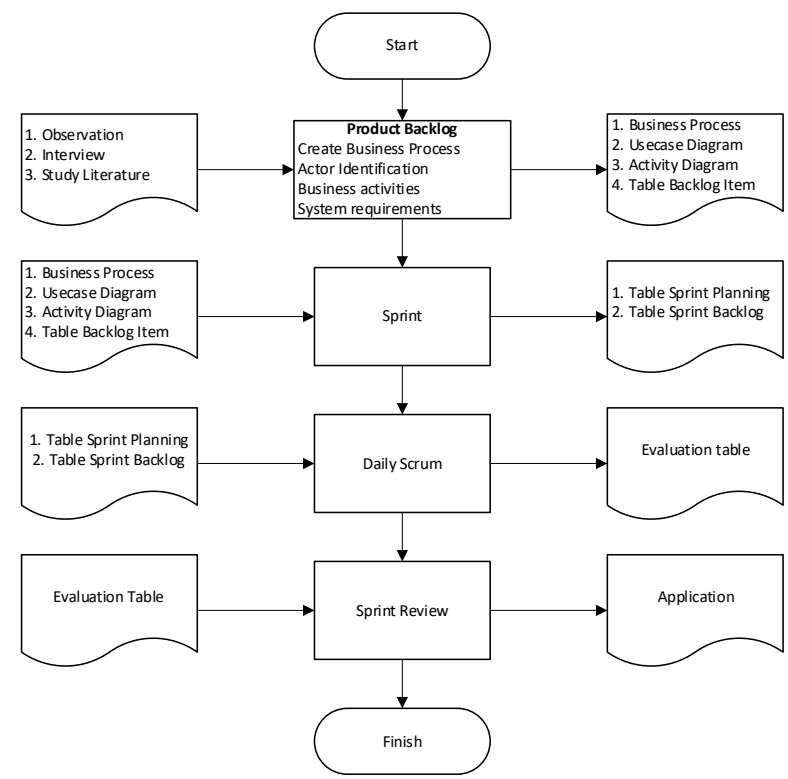

Figure 2. Research Framework

\subsection{Work Breakdown Structure (WBS)}

The process of the stages of work in the design of applications carried out during the study and is described by the work breakdown structure as an objective to explain the research and research stages that are adjusted to the Scrum, as well as the activities that will be carried out at each of these stages presented in the WBS scheme [21], [22]. In Figure 3 explains the stages of the Work Breakdown Structure.

In the first stage in this WBS is the product backlog at this stage has the activity of making business processes, obtained from documents, interviews, reference books and previous research journals, then the next activity is the identification of actors who will be described by use case diagrams, the next activity is identify business activities that are illustrated with activity diagrams, the next activity is to create a system structure that will be illustrated with class diagrams, and identify system requirements that will be illustrated by the backlog item table. 


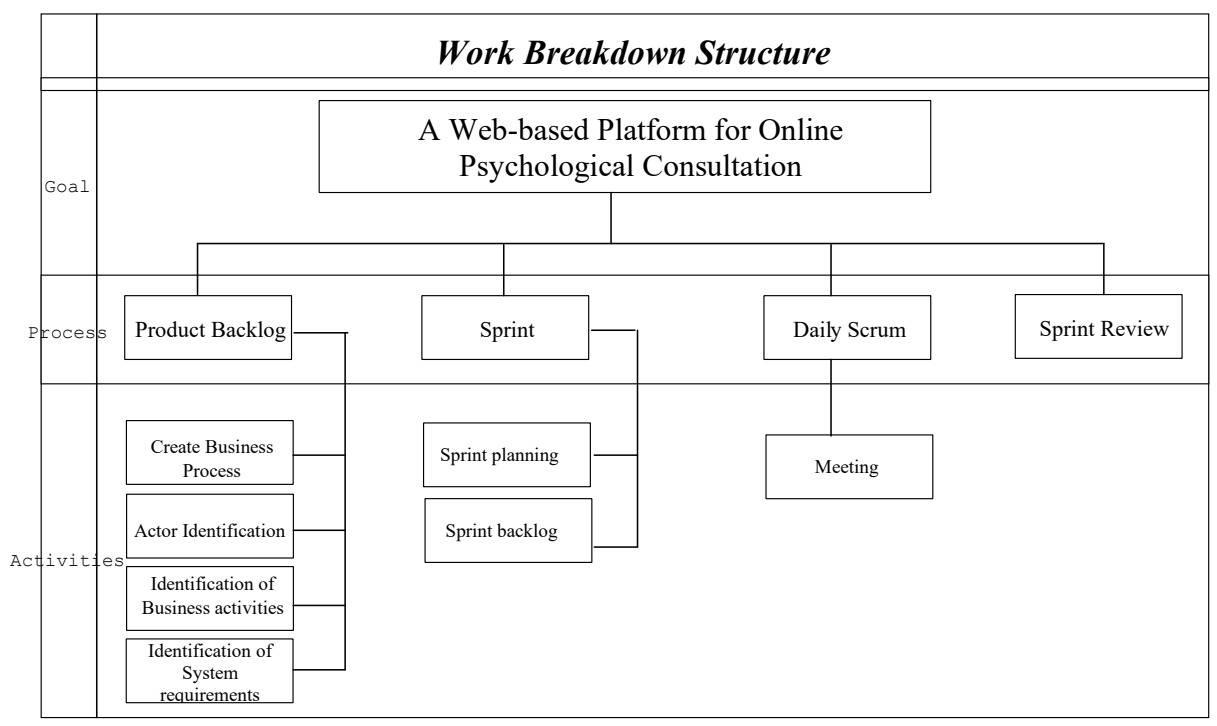

Figure 3. Work Breakdown Structure

In the sprint stage that is designing the process of activities that will be carried out to create a system of backlog items developed by making a planning table. Furthermore, the daily scrum stage is carried out at this stage resulting in an evaluation table of the results of the sprints that have been completed. Furthermore, the sprint review stage in which this stage is the last stage that is implementing the results of the system that has been made.

\section{RESULTS AND DISCUSSION}

\subsection{Product Backlog}

Product Backlog is the first stage, in which at this stage produces several activities including making business processes, identifying actors, identifying business activities, creating a system structure, identifying system requirements to be presented as follows:

\section{Create Business Process}

The business process carried out is making a design that is built by describing the activities to be carried out by the user. Figure 4 is the design of activity diagrams about business processes, which are obtained based on data through observation, interviews, and literature studies.

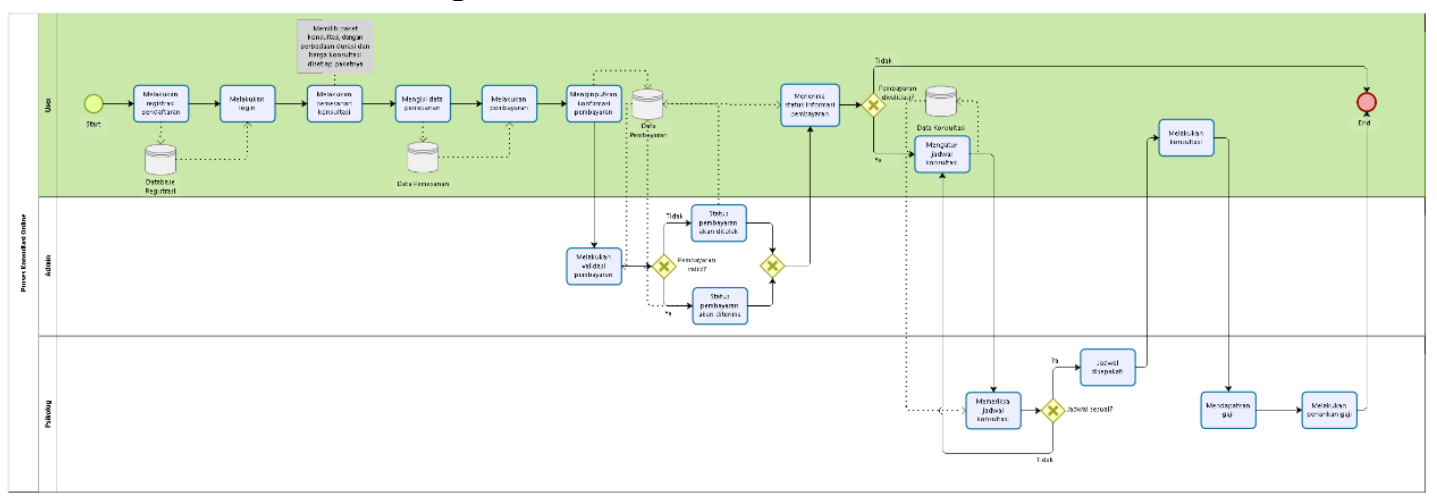

Figure 4. Business processes

\section{Actor Identification}

After designing the business process that will be built, the next stage is to identify the actors where this stage aims to identify the targets that will be involved in this system. The identified actors are shown in Figure 5. 


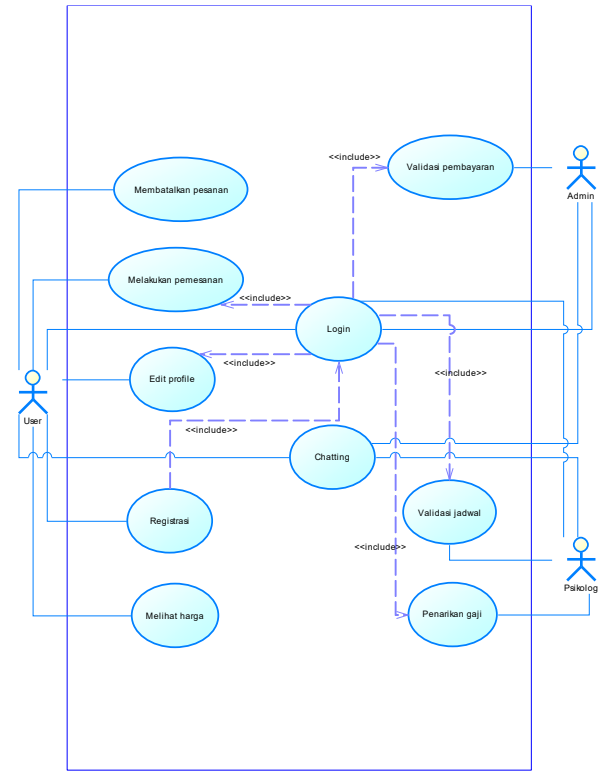

Figure 5. Actors Identification

\section{Identification of Business Activities}

Activity diagram is used to identify business activities of a system, this diagram is made based on the use case scenario that has been made, the following is an activity diagram of a online psychological consultation that is presented in Figure 6 below.

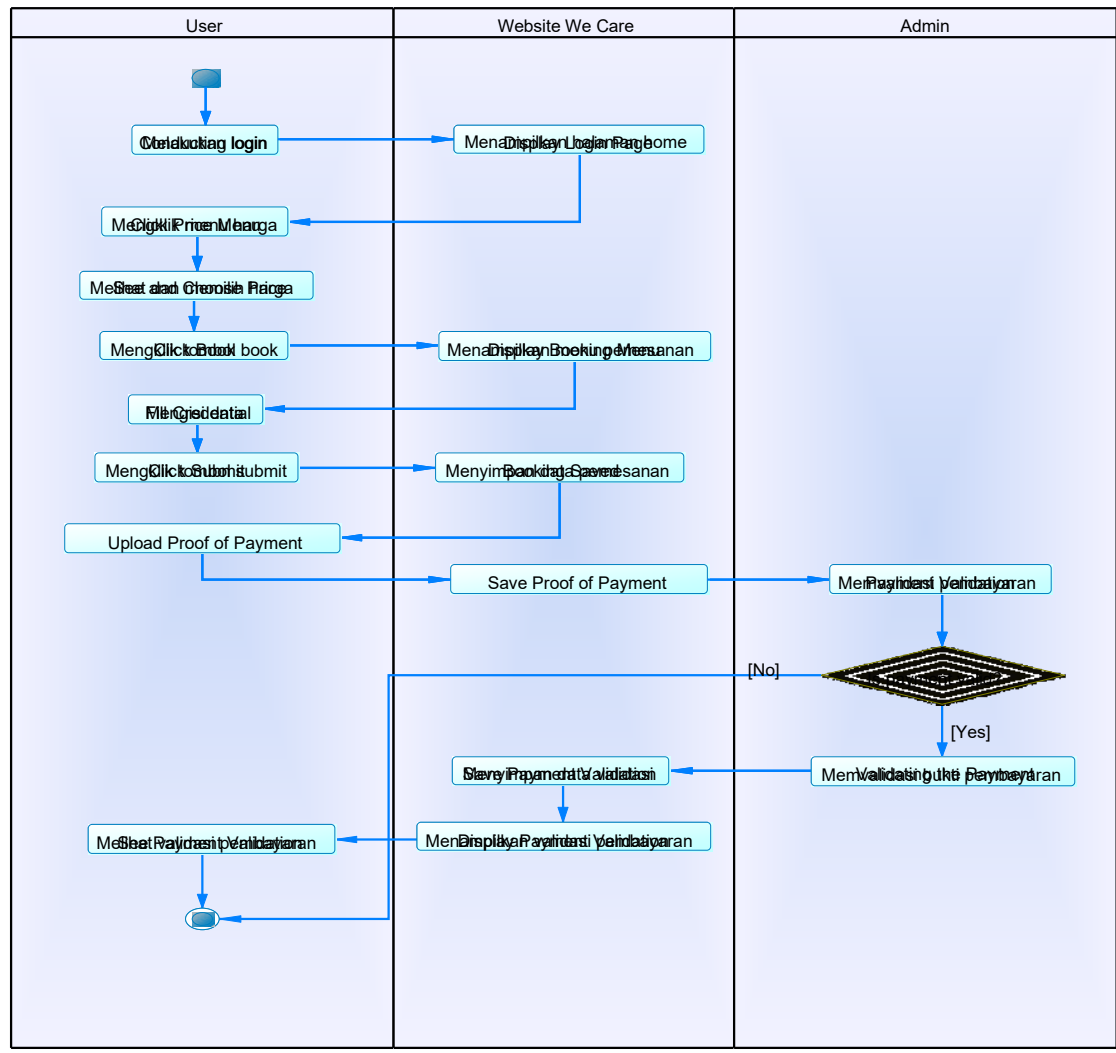

Figure 6. Activity Diagram

\section{System Requirement Identification}

System requirements identification is the stage carried out to analyze system requirements, in terms of application program needs to be presented in Table 1 as follows: 
Table 1. Backlog Items

\begin{tabular}{cl}
\hline No & \multicolumn{1}{c}{ Backlog Item } \\
\hline 1 & Psychologists are able to access psychologist pages \\
2 & Users are able to access user pages \\
3 & Admins are able to access the admin page \\
4 & The user is able to see consultation package information data \\
5 & Users are able to book packages \\
6 & Users are able to chat with psychologists \\
7 & Users are able to see transaction history \\
8 & Users are able to make transactions \\
9 & Psychologists are able to add, delete and update consultation packages \\
10 & Users are able to provide a review after the consultation is complete \\
11 & The system will automatically cancel the booking when no payment is made \\
\hline
\end{tabular}

\subsection{Sprint}

Sprint is the second stage, where at this stage there are two activities, namely: sprint planning and sprint backlog which will be presented below:

1. Sprint Planning

Sprint planning is the stage carried out after establishing the product backlog. A briefing/meeting is held by the Scrum Team at the beginning of each sprint to evaluate the product backlog, discuss the purpose and mission of each feature, at this point the Scrum Team determines the time needed for each member to carry out each feature, which depicted in Table 2 as follows:

Table 2. Sprint Planning

\begin{tabular}{lll}
\hline No & Sprint Planning & Estimated Time \\
\hline 1 & Login & 2 \\
2 & Homepage & 4 \\
3 & Booking & 6 \\
4 & Transaction & 6 \\
5 & Consultation Process (Chatting) & 7 \\
6 & Category & 5 \\
7 & Review & 4 \\
\hline
\end{tabular}

\section{Sprint Backlog}

At this stage that is designing a sprint backlog where at this stage is making a list of needs that are the priority of users with the work time that has been determined by the team, in this section that is completing features that have been defined in the product backlog and sprint planning, which will be presented in Table 3:

Table 3. Sprint Backlog

\begin{tabular}{|c|c|c|c|c|c|c|c|c|}
\hline \multirow{2}{*}{ Sprint 1} & \multirow{2}{*}{ Execution } & \multicolumn{7}{|c|}{ Estimated Time (Hour) } \\
\hline & & 1 & 2 & 3 & 4 & 5 & 6 & 7 \\
\hline \multirow{5}{*}{ LOGIN } & Create Database & 2 & & & & & & \\
\hline & Design User Interface & 2 & 1 & & & & & \\
\hline & Coding & & 6 & 5 & & & & \\
\hline & Testing & & 2 & 2 & & & & \\
\hline & Total & & & & $\mathrm{n}$ & & & \\
\hline
\end{tabular}

Sprint 1 consists of 4 jobs with a total estimated time of 20 hours, in this sprint create a login page for users, psychologists, admins after sprint 1 is finished, then the next sprint will be continued.

\subsection{Daily Scrum}

Daily Scrum is the third stage where at this stage produces meeting activities. At this stage practices are carried out to monitor performance, meetings are conducted to report on features that 
are being developed, and at the end of the meeting, an update will be made at each completion time to find out the remaining work done during the sprint process.

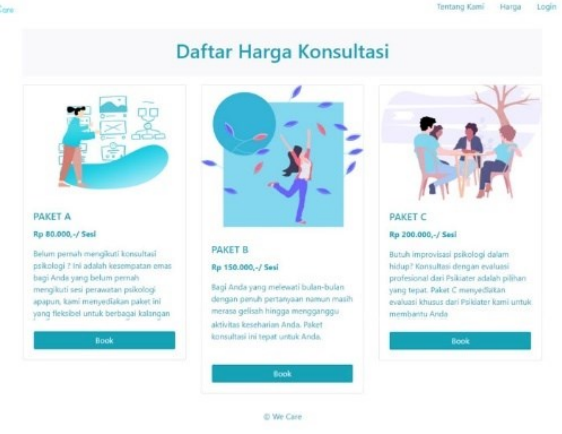

Figure 7. Main User Interface

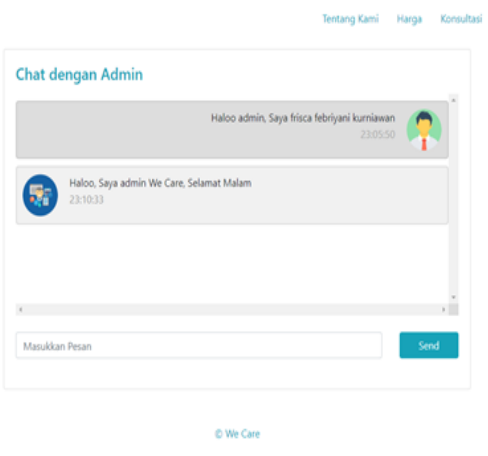

Figure 8. Chatting Feature

Figure 7 is the main user interface platform, on this page users and psychologists can access the page without having to log in first, both users and psychologist can see the products that exist in the application. While Figure 8 is one of the main interface features, namely the chat feature. In this feature, the user can do a question and answer consultation with a psychologist. And users and psychologists can send messages to the admin.

\section{CONCLUSION}

Mental health problems or mental illness can cause various emotional symptoms, weight loss, malnutrition, electrolyte imbalance caused by vomiting by yourself. Ways to determine the diagnosis and check whether you have a mental illness, there are several ways in the form of physical examination through a doctor, laboratory tests, psychological evaluation. There is also therapy as a healing process and recovery of the soul that is healthy. In Indonesia, many people experience mental health problems, but most are not aware of and care about these problems. Even in the worst cases, many cases lead to suicide. Deaths from suicide in Indonesia are predicted to be the highest in Southeast Asia. One of the factors triggering suicide is people who experience mental health problems do not have a place to talk about the problems they are facing, because in every city itself not all the availability of psychologist services that can help sufferers of mental health problems, especially considering the price psychologist services offered are quite expensive. The development of information technology at this time has been developing very rapidly in a society wherein the development of information technology has become a part of people's lives today. Therefore, by taking into account these considerations, the WeCare project proposes developing a web-based platform for online psychologist consultation. In general, this platform has three main actors namely, admin, user, and psychologist.

\section{REFERENCES}

[1] W. H. O. D. of Mental Health et al., Mental health atlas 2005. World Health Organization, 2005.

[2] M. Jahoda, "Current concepts of positive mental health.," 1958.

[3] C. S. Mackenzie, W. L. Gekoski, and V. J. Knox, "Age, gender, and the underutilization of mental health services: The influence of help-seeking attitudes," Aging Ment. Heal., vol. 10, no. 6, pp. 574$582,2006$.

[4] D. S. Elliott, D. Huizinga, and S. Menard, Multiple problem youth: Delinquency, substance use, and mental health problems. Springer Science $\backslash \&$ Business Media, 2012.

[5] Y. Lu, "Mental health and risk behaviours of rural--urban migrants: Longitudinal evidence from Indonesia," Popul. Stud. (NY)., vol. 64, no. 2, pp. 147-163, 2010.

[6] S. Duhita, "Mahalnya Biaya Melawan Depresi dan Menjaga Kesehatan Mental di Indonesia [The High Cost of Fighting Depression and Maintaining Mental Health in Indonesia]," Vice Indonesia, 2018. [Online]. Available: https://www.vice.com/id_id/article/435gkw/mahalnya-biaya-melawan-depresidan-menjaga-kesehatan-mental-di-indonesia. [Accessed: 01-Apr-2020].

[7] M. Rumetna, E. E. Renny, and T. N. Lina, "Designing an Information System for Inventory Forecasting:(Case Study: Samsung Partner Plaza, Sorong City)," Int. J. Adv. Data Inf. Syst., vol. 1, no. 2, pp. 80-88, 2020. 
[8] L. Setiyani, A. Syamsudin, A. Gintings, and D. Arifin, "The Analysis of Functional Needs on Undergraduate Thesis Information System Management: A Case Study in Indonesian Universities," Int. J. Adv. Data Inf. Syst., vol. 1, no. 2, pp. 50-59, 2020.

[9] B. A. Sulakono, S. Sarkum, M. H. Munandar, M. Masrizal, and D. Irmayani, "The Diversity of Labuhanbatu Community Culture in Android-Based Applications," Int. J. Adv. Data Inf. Syst., vol. 1, no. 2 , pp. $60-68,2020$.

[10] N. R. Kowtha and T. W. I. Choon, "Determinants of website development: a study of electronic commerce in Singapore," Inf. I\& Manag., vol. 39, no. 3, pp. 227-242, 2001.

[11] R. McLeod and G. P. Schell, Management information systems. Pearson/Prentice Hall USA, 2007.

[12] P. B. Kruchten, "The 4+ 1 view model of architecture," IEEE Softw., vol. 12, no. 6, pp. 42-50, 1995.

[13] A. Cockburn, Writing effective use cases. Addison-Wesley Professional, 2000.

[14] R. M. Bastos and D. D. A. Ruiz, "Extending UML activity diagram for workflow modeling in production systems," in Proceedings of the 35th Annual Hawaii International Conference on System Sciences, 2002, pp. 3786-3795.

[15] S. Swaminathan and C. Smidts, "The event sequence diagram framework for dynamic probabilistic risk assessment," Reliab. Eng. I\& Syst. Saf., vol. 63, no. 1, pp. 73-90, 1999.

[16] X. Li, Z. Liu, and H. Jifeng, "A formal semantics of UML sequence diagram,” in 2004 Australian Software Engineering Conference. Proceedings., 2004, pp. 168-177.

[17] A. Cockburn and J. Highsmith, "Agile software development, the people factor," Computer (Long. Beach. Calif)., vol. 34, no. 11, pp. 131-133, 2001.

[18] K. Beck et al., "Manifesto for agile software development," 2001.

[19] K. Schwaber and M. Beedle, Agile software development with Scrum, vol. 1. Prentice Hall Upper Saddle River, 2002.

[20] M. Cohn, Agile estimating and planning. Pearson Education, 2005.

[21] R. C. Tausworthe, "The work breakdown structure in software project management," J. Syst. Softw., vol. 1, pp. 181-186, 1979.

[22] K. H. Pries and J. M. Quigley, Scrum project management. CRC press, 2010. 